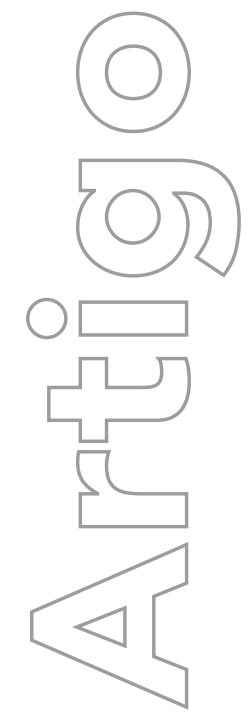

\title{
Território, jurisdição e ciberespaço: entre os contornos westfalianos e a qualidade transfronteiriça da Internet
}

\author{
Carolina Batista Israel \\ Universidade Federal do Paraná \\ Curitiba, PR, Brasil \\ e-mail: carol_israel@riseup.net
}

revista

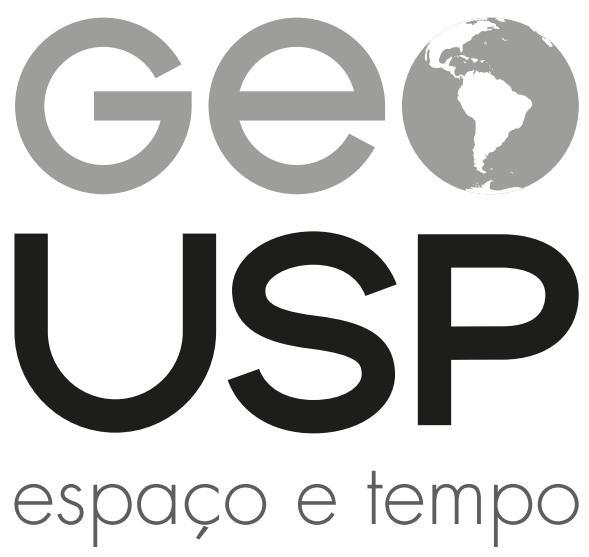

Volume $24 \cdot n^{\circ} 1(2020)$

ISSN 2179-0892 p. $69-82$

Como citar este artigo:

ISRAEL, C. B. Território, jurisdição e ciberespaço: entre os contornos westfalianos e a qualidade transfronteiriça da Internet. Geousp - Espaço e Tempo (On-line), v. 24, n. 1, p. 69-82, abr. 2020. ISSN 2179-0892.

Disponível em: https://www.revistas.usp.br/geousp/ article/view/161521. doi: https://doi.org/10.11606/ issn.2179-0892.geousp.2020.161521.

\section{(c) (1)}

Este artigo está licenciado sob a Creative Commons Attribution 4.0 License. 


\section{Território, jurisdição e ciberespaço: entre os contornos westfalianos e a qualidade transfronteiriça da Internet}

\section{Resumo}

Usualmente colocadas em oposição ao território, as redes digitais que conformam o ciberespaço são analisadas neste artigo a partir de sua ancoragem espacial. A territorialidade do ciberespaço é restituída aqui em sua relação com o território jurisdicional dos Estados nacionais, como um objeto técnico com características espaciais concomitantemente opostas e complementares, produzindo dinâmicas transfronteiriças ao mesmo tempo em que se nacionaliza dentro dos limites westfalianos. Investigamos essa oposição complementar com base em casos concretos que nos permitem verificar o movimento do ciberespaço não apenas como gerador de dinâmicas transnacionais, mas como um espaço que permite o exercício de uma multiterritorialidade jurisdicional, com a qual determinados Estados atuam extraterritorialmente, normatizando outras soberanias. Com base em tal exploração, examinamos as implicações das redes digitais nas configurações territoriais westfalianas, assim como o impacto dessa tecnologia no conceito de território, reiterando, afinal, a pertinência dessa categoria geográfica para o estudo do ciberespaço.

Palavras-chave: Território. Jurisdição. Ciberespaço. Internet. Fronteiras.

\section{Territory, jurisdiction and cyberspace: between Westphalian contours and the cross-border quality of the Internet}

\footnotetext{
Abstract

Usually placed in opposition to the territory, the digital networks that make up cyberspace are analyzed in this article from their spatial anchorage. The territoriality of cyberspace is here restored in its relation to the jurisdictional space of national states, as a technical object with concomitantly opposite and complementary spatial characteristics, producing transboundary dynamics while nationalizing within Westphalian boundaries. We investigate this complementary opposition based
} 
on concrete cases that allow us to verify the movement of cyberspace not only as a generator of transnational dynamics, but as a space that allows the exercise of jurisdictional multiterritoriality, with which certain states act extraterritorially regulating other sovereignties. Based on this exploration, we examine the implications of digital networks on Westphalian territorial configurations, as well as the impact of this technology on the concept of territory, reiterating, after all, the relevance of this geographical category to the study of cyberspace.

Keywords: Territory. Jurisdiction. Cyberspace. Internet. Borders.

\section{Territoire, juridiction et cyberespace: entre les contours westphaliens et la qualité transfrontalière de l'Internet}

\section{Résumé}

Habituellement placés en opposition au territoire, les réseaux numériques qui composent le cyberespace sont analysés dans cet article à partir de leur ancrage spatial. La territorialité du cyberespace est ici restaurée dans ses relations avec l'espace juridictionnel des États nationaux, en tant qu' objet technique présentant simultanément des caractéristiques spatiales opposées et complémentaires, produisant une dynamique transfrontalière tout en se nationalisant à l'intérieur des frontières westphaliennes. Nous étudions cette opposition complémentaire étayée par des cas concrets, nous permettant de vérifier le mouvement du cyberespace non seulement en tant que générateur de dynamiques transnationales, mais également en tant qu' espace permettant l'exercice d'une multiterritorialité juridictionnelle, avec laquelle certains États agissent de manière extraterritoriale, en réglementant d'autres souverainetés. Sur la base de cette exploration, nous examinons les implications des réseaux numériques sur les configurations territoriales westphaliennes, ainsi que l'impact de cette technologie sur le concept de territoire, en rappelant, après tout, la pertinence de cette catégorie géographique pour l'étude du cyberespace.

Mots-clés: Territoire. Juridiction. Cyberespace. Internet. Frontières. 


\section{Quando o ciberespaço e o território se encontram}

Ao colocar lado a lado os termos ciberespaço e jurisdição, nos encontramos em face de dois elementos que parecem estar em oposição na forma como operam espacialmente, constituindo hoje um dos principais dilemas no exercício dos limites territoriais westfalianos e, consequentemente, das relações interestatais. A lógica de operação da jurisdição diz respeito ao exercício da soberania de um Estado-nação em dado território delimitado por fronteiras claras. Entende-se por fronteiras claras que os limites desse território devem ser reconhecidos não apenas por seus compatriotas, mas sobretudo externamente, por outras unidades territoriais similares, ou seja, pelos demais Estados-nações, num reconhecimento mútuo de seus espaços jurisdicionais.

OTratado de Westfália, 'de 1648, é unanimemente reconhecido como o marco histórico que estabeleceu o princípio da soberania dos Estados-nações sobre seus respectivos territórios e, com isso, o preceito da não ingerência extraterritorial, restringindo o poder do soberano aos limites internos de suas fronteiras. Assim, o sistema westfaliano, base do princípio jurídico desde então, compreende uma ordem externa, pelo reconhecimento do direito de outros Estados à soberania, admitindo-os como iguais, e uma ordem interna, que diz respeito à autoridade exclusiva do governo sobre seu território e sua população, configurando uma ordem internacional como conjunto de unidades territoriais equivalentes (Arroyo, 2004).

Entretanto, num contexto político mundial baseado em fronteiras, a ordem espacial transfronteiriça do ciberespaço perturba o exercício do poder sobre fatos nacionais, na medida em que estes agora se espraiam pelo globo. É importante observar que os fenômenos se distribuem, mas não deixam de existir ou de estar localizados. A despeito do persistente imaginário que proclama o espaço virtual como despregado do espaço geográfico, a Internet, base material do ciberespaço, não é uma entidade a-espacial, nem um mundo paralelo. A Internet é um constructo técnico complexo e multifacetado, que se desenvolve não apenas sobre, mas com o espaço geográfico, fazendo parte de seu conteúdo e produzindo novas configurações e qualidades que desafiam nossa compreensão euclidiana do espaço político westfaliano.

\section{Sobre os contornos do ciberespaço}

Nos primórdios da Internet, na década de 1980, acreditava-se que a rede mundial de computadores emanciparia a humanidade dos constrangimentos do mundo físico e das distâncias, numa "exultação sem corpo do ciberespaço", como definiu William Gibson (2008[1984]) na obra de ficção científica Neuromancer. Na década de 1990, a declaração de independência do ciberespaço, de John Perry Barlow, ${ }^{2}$ ficou igualmente registrada como esse imaginário (e anseio) de que o espaço virtual, paralelo ao espaço geográfico, estaria acima dos Estados nacionais:

Os governos derivam seu justo poder a partir do consenso dos governados. Vocês não solicitaram ou receberam o nosso. Não convidamos vocês. Vocês não vêm do espaço cibernético, o novo lar da Mente. Não temos governos eleitos, nem mesmo é provável que tenhamos um [...]. O espaço cibernético não se limita a suas fronteiras [...]. Estamos formando nosso próprio Contrato Social. Essa maneira de governar surgirá de acordo

Conjunto de acordos entre Estados europeus que pôs fim a um longo período de guerras.

2 Fundador da Electronic Frontier Foundation, ONG dedicada à preservação do direito à liberdade de expressão. 
com as condições do nosso mundo, não do seu. Nosso mundo é diferente [...]. Nosso mundo é um mundo que está em toda parte e em lugar nenhum, mas não é onde moram os corpos (Barlow, 1996).

Como salientamos, a Internet, base técnica do ciberespaço, não opera no vazio. Tratase de uma tecnologia de compressão espaço-tempo que depende e é o resultado da fixidez espacial do mundo concreto por meio dos pontos de acesso, da fisicalidade e da materialidade dos cabos oceânicos que conectam os continentes. Embora o aspecto gráfico, a resiliência e a instantaneidade da informação façam parecer que os dados pairam atrás da tela, não há nada no ciberespaço que não esteja situado e armazenado em algum computador, ou seja, em coordenadas geográfica precisas. Assim, o tamanho da resiliência e da ubiquidade do espaço virtual é a medida exata da distribuição geográfica dos aparatos técnicos que lhe subjazem.

O ciberespaço é feito desses espaços com atributos e qualidades específicas e, ao mesmo tempo, altera as dinâmicas dos lugares onde incide. "O mundo 'virtual' depende de e, mais ainda, configura as multiplicidades do espaço físico" (Massey, 2008, p. 146).

\section{A reticulação ciberespacial dos territórios westfalianos}

Em termos práticos, o ciberespaço se concretiza territorialmente com qualidades transfronteiriças de operação e circulação de dados. Assim, um simples e-mail enviado do Brasil para a Índia por meio de uma conta da empresa estadunidense Microsoft (Hotmail), cuja central de dados está na Irlanda, envolve no mínimo quatro jurisdições diferentes. Ou seja, a Internet cria atividades, atores e espaços transfronteiriços que não se sobrepõem ponto a ponto ao território westfaliano tradicional, mas que tecem uma rede de relações através de uma rede de objetos. Essa discrepância entre a lógica espacial das atividades transnacionais e o paradigma territorial jurisdicional, baseado em fronteiras, conduziram na década de 1990 não apenas a declarações apaixonadas como a de Barlow, mas também a afirmações de teóricos que anunciavam o fim dos territórios, título do livro de Bertrand Badie (1995b), o qual o autor popularizou em palestras como "La fin des territoires westphaliens" (Badie, 1995a).

Badie parte de uma perspectiva que entende a relação entre rede e território como lógicas espaciais que se situam numa oposição binária e irreconciliável. Portanto, um mundo onde o exercício do poder se transnacionaliza estaria fadado ao fim dos territórios. No mesmo colóquio ("Le territoire, lien ou frontière?") em que Badie (1995a) apresenta sua fala sobre "o fim dos territórios westfalianos", Yves Lacoste (1995) contra-argumenta com a comunicação "Encore et toujours des territoires", opondo-se à retórica do primeiro.

Lacoste sustenta como princípio de entendimento do conceito de território uma relação de apropriação espacial que pode assumir diversas formas, inclusive sobreposições e emaranhados. Nesse sentido, reconhece que a territorialização de um Estado pode assumir contornos mais complexos do que os tradicionais e evidentes limites da jurisdição. Reconhece igualmente que o território não se restringe a uma relação espacial exclusiva do Estado. Direta e pontual, sua crítica a Badie concentra-se no fato de que sua formulação contém uma:

[...] concepção única do território do Estado-nação e funciona apenas em um nível de análise. Nesse sentido, pode se falar de ilusão cartográfica. Penso, do meu lado, que devemos considerar os problemas dos territórios em diferentes níveis de análise e em seus 
emaranhados [enchevêtrements], ${ }^{3}$ considerando que esses emaranhados [enchevêtrements] são parte da realidade das coisas e que a melhor maneira de evitar que eles não degenerem em catástrofes, é levá-los em consideração ${ }^{4}$ (Lacoste, 1995, p. 3, tradução nossa).

Concordamos com a perspectiva de que o território se define sobretudo pelo processo de apropriação espacial e pelo poder que nele se exerce, independentemente de sua forma, zonal ou em rede, e dos sujeitos que protagonizam a ação, quer sejam esses o Estado, as empresas ou a sociedade civil. Essa concepção de território nos permite reler o exercício da atividade política e jurisdicional em tempos de globalização e, principalmente, compreender o ciberespaço a partir da lógica socioespacial de sua base, a Internet.

\section{A territorialidade jurisdicional para além das fronteiras westfalianas}

Considerando os argumentos supracitados, partimos do pressuposto de que a complexificação do modelo westfaliano não implica o fim dos territórios, pois não há processo de desterritorialização sem que haja um movimento concomitante de reterritorialização (Haesbaert, 2007). Na medida em que uma entidade, uma empresa ou plataforma de Internet se desterritorializa do seu solo originário - ainda que parcialmente, pois mantém sua sede no país de origem - e se reterritorializa dentro dos limites de outro Estado-nação, verifica-se um processo de sobreposição de territórios, ou enchevêtrements (Lacoste, 1995), produzindo uma multiterritorialidade com pluralidade de jurisdições.

A esta capacidade de organizações não estatais, estrangeiras ou não, normatizarem o território, Antas Jr. (2004, 2005) denomina pluralismo jurídico. O autor observa que o monismo jurídico do ocidente sempre foi um agenciamento socioespacial mais aparente do que um fato propriamente dito. As transformações do fim do século XX, entretanto, tornaram a relação entre território e regulação um tema incontornável, tratado por Badie como o fim dos territórios, por Lacoste como um emaranhado e sobreposição, mas cuja peculiaridade assenta-se, finalmente, na "capacidade das corporações transnacionais e das organizações sociais bem estruturadas de criarem novas juridicidades que influem na vida de todos que vivem num mesmo território" (Antas Jr., 2005, p. 69).

Quando plataformas de relacionamento social, como o Facebook ou Twitter, operam em jurisdições outras que não a de seu país sede, levam consigo direta ou indiretamente normas exteriores a esses territórios. Indiretamente, pela normatividade técnica embutida na própria estrutura desses espaços algorítmicos que regulam as ações possíveis e seus limites, o que podemos ou não fazer dentro desses espaços, refletindo os valores da sociedade que os criou. E diretamente, pela sujeição dos usuários de diversas nações aos Termos de Uso que constituem em si uma jurisdição, regulando de modo privado as interações sociais que ocorrem dentro de seus "jardins murados", criando espaços com suas próprias normas ditos globais, mas que expressam valores morais específicos de determinadas sociedades.

3 Nesse contexto, a palavra enchevêtrements também pode ser traduzida por "sobreposições".

4 " $[. .$.$] conception unique du territoire de l'Etat-nation et ne fonctionne qu'à un seul niveau d'analyse. En ce sens,$ il peut effectivement parler d'illusion cartographique. Je pense, de mon côté, qu'il faut envisager les problèmes de territoires à différents niveaux d'analyse et dans leurs enchevêtrements, en considérant que ces enchevêtrements font partie de la réalité même des choses et que le meilleur moyen d'éviter qu'ils ne dégénèrent en catastrophes, est d'en tenir compte" (Lacoste, 1995, p. 3). 
Em 2015, o Facebook bloqueou uma foto histórica de 1909 que mostrava uma indígena com o seio exposto. A foto fora postada na plataforma dessa rede social, na página do Ministério da Cultura, por ocasião do lançamento do portal Brasiliana Fotográfica Digital, cuja proposta é tornar público um acervo digital de fotos históricas. Questionada pelo Ministério da Cultura, a rede social alegou ter normas próprias aplicadas globalmente, não se submetendo a legislações nacionais, conforme relatado em matéria da EBC (Leal, 2015).

Embora o Facebook tenha restituído a foto à página do Ministério da Cultura dois dias depois, esse é um dos exemplos flagrantes dos limites do discurso da globalização e dos possíveis conflitos da coexistência de jurisdições que adotam práticas culturais divergentes no âmbito das redes digitais.

Contudo, uma das questões mais sensíveis que perpassam a relação entre jurisdição e ciberespaço diz respeito à localização do armazenamento de dados dos usuários das plataformas digitais, já que esse fator pode ser determinante na conclusão sobre a jurisdição a que eles pertencem, uma vez que o argumento locacional tem sido a principal base das decisões judiciais na resolução de conflitos. Nesse caso, o desafio é determinar se os dados pertencem à jurisdição do país onde foram produzidos (um usuário brasileiro do Hotmail, por exemplo), do país onde estão armazenados (o data center da empresa, localizado na Irlanda) ou do país onde fica a sede da empresa cujos serviços foram utilizados para gerá-los (os EUA, no caso dessa empresa).

$O$ atual litígio entre o Departamento de Justiça dos EUA e a Microsoft (Thielman, 2015; Ellingsen, 2016), que se desenrola há quatro anos, é ilustrativo do impasse descrito acima. Em 2013, com base na Lei de Comunicações Armazenadas, de 1986 (Stored Communications Act), o Departamento de Justiça dos EUA executou um mandado de busca nessa empresa requerendo acesso aos e-mails de uma conta Hotmail de um suspeito em envolvimento com narcotráfico cuja nacionalidade não foi divulgada, embora alguns jornais apontem ser irlandesa. Como a referida lei não é aplicável extraterritorialmente, a Microsoft se negou a entregar os dados alegando que eles estariam armazenados num data center na Irlanda. O Departamento de Justiça replicou com o argumento de que, embora os dados estivessem alocados no exterior, poderiam ser acessados a partir do solo estadunidense.

Para o Departamento de Justiça, sendo a Microsoft uma empresa estadunidense, tudo o que ocorre dentro de suas fronteiras digitais é passível de ser arrolado judicialmente pelo governo, e seus dados repatriados, caso se encontrem fora do país. Embora em 2016 a Microsoft tenha ganhado a causa, em 2017, o Departamento de Justiça recorreu ao Supremo Tribunal Superior pedindo revisão da decisão.

Esse litígio é relevante não só como caso expressivo da indeterminação da jurisdição de fenômenos transfronteiriços que envolvem o ciberespaço, mas principalmente porque cria jurisprudência para ações futuras, caso a Suprema Corte venha a reconhecer o direito do governo de acessar esses dados. Uma decisão nesse sentido significaria a anuência formal das instâncias jurídicas estadunidenses, corroborando a prática de acesso por parte do governo a dados de cidadãos estrangeiros que utilizam serviços de plataformas digitais cuja sede esteja dentro de suas fronteiras, independentemente de onde os dados tenham sido gerados ou onde estejam alocados.

Assim, por meio do uso de plataformas sediadas nos EUA, observamos a jurisdição desse país aplicar-se em escala extraterritorial, ou seja, para além de suas fronteiras westfalianas, compondo geograficamente o exercício de uma multiterritorialidade transnacional, mediando a relação de diferentes culturas num processo de globalização centrípeta. Basta calcular o número 
de serviços digitais prestados por empresas estadunidenses em todo o mundo para tornar explícita a importância dessa centralização de poder.

A esse processo de interpenetração de jurisdições, denominada pluralismo jurídico por Antas Jr., Bertrand de La Chapelle designa como uma fractalização da soberania, caracterizada pelo exercício da autoridade de um governo externamente aos limites outrora euclidianos de suas fronteiras. A configuração geométrica de uma forma fractal é caracterizada pela descontinuidade, um ponto podendo pertencer a dois espaços distintos (De La Chapelle, 2012).

Partindo do conceito de multerritorialidade, Haesbaert desenha o conceito de territóriozona para descrever o exercício da territorialidade em um espaço contíguo, como a do Estado nacional westfaliano. Quanto ao território-rede, sua lógica reside na própria descontinuidade como estratégia de apropriação espacial.

Aqui, a perspectiva euclidiana de um espaço-superfície contínuo praticamente sucumbe à descontinuidade, à fragmentação e à simultaneidade de territórios que não podemos mais distinguir claramente onde começam e onde terminam ou, ainda, onde irão "eclodir", pois formações rizomáticas também são possíveis (Haesbaert, 2007, p. 348).

As redes técnicas que formam o espaço virtual constituem territórios-rede privados que respondem, no plano legal, à jurisdição dos Estados westfalianos, organizados em zonas. $\mathrm{Na}$ medida em que determinados Estados exercem um poder privilegiado sobre essas redes privadas natas em seu território, como para obter informações e influir na dinâmica espacial de outras jurisdições, essa ordem de relações torna-se um mecanismo de exercício de uma multiterritorialidade westfaliana da era digital, incidindo muitas vezes como uma verticalidade espacial interestatal, pois geradora de desordens.

Posto que os Estados nações vêm enfrentando as contradições da superposição de territórios digitais em sua jurisdição, passam a se desenvolver estratégias de projeção de sua autoridade sobre a Internet, numa busca de reterritorialização westfaliana do ciberespaço.

Com a proeminência mundial de empresas como Google, Apple, Facebook, Amazon - usualmente representadas pelo acrônimo Gafa -, a preocupação dos Estados nacionais com o exercício de sua soberania tem repousado hoje muito mais na gestão de conteúdo, na localização de dados e na topologia dos fluxos na Internet do que no debate sobre a governança dos recursos críticos, que envolvem a centralidade geográfica do sistema de nomes de domínio (Domain Name System - DNS) e da Internet Corporation for Assigned Names and Numbers (Icann), igualmente sob jurisdição dos EUA. ${ }^{5}$

A atual configuração topológica da Internet conduziu a uma inversão de seu modelo conceitual, tanto no que diz respeito à sua infraestrutura física de cabos submarinos, quanto aos servidores que hospedam conteúdos e às empresas proprietárias das plataformas digitais. Concebida para ser distribuída, a rede mundial de computadores tornou-se um modelo concentrado em termos de circulação de informação, dentro de um sistema no qual os EUA se tornaram privilegiados na geração de valor pelo controle e exploração de dados.

5 Sobre a centralidade político geográfica que a lógica espacial do DNS gera, ver Pires (2012). 


\section{Nacionalização de dados e estratégias de geodirecionamento: decalque da jurisdição westfaliana na Internet?}

Diante das assimetrias de poder na regulação do ciberespaço acima descritas, a reação de determinados países que exercem um maior controle sobre a Internet em seu território tem se dirigido à demanda de instalação de servidores em solo nacional aos provedores de aplicação, para que os dados de seus cidadãos estejam sob sua jurisdição. $\bigcirc$ Brasil chegou a cogitar a inclusão da obrigatoriedade da guarda nacional de dados no Marco Civil da Internet, à época das revelações de Edward Snowden, ${ }^{6}$ embora esse requisito não tenha sido integrado à redação final da referida lei.

Quanto à administração de conteúdos, observam-se duas tendências de estratégias para adequá-los às leis nacionais. A primeira é a filtragem de sites e conteúdos disponíveis dentro de suas fronteiras, através de seus próprios provedores de acesso à Internet, estratégia adotada pela Rússia, pela China e pelo Irã, enquanto outros países optam por demandar a filtragem ao próprio provedor de conteúdo, seja acionando diretamente a companhia, seja por via jurídica, com processos na justiça.

Representativo deste último caso é um episódio do começo dos anos 2000, quando uma organização francesa acionou a justiça de seu país para que a empresa estadunidense Yahoo não disponibilizasse o leilão de objetos nazistas em seu portal on-line dentro dessa jurisdição, já que na França são proibidas a apologia a crimes de guerra e a difusão de insígnias nazistas (Gros, 2004).

Quando se filtra a partir do provedor de conteúdos, utiliza-se a geolocalização dos IPS associados à jurisdição para onde a filtragem deve ocorrer, tornando determinados conteúdos indisponíveis para esse destino. O protocolo IP (Internet Protocol) é responsável pelo endereçamento das comunicações entre computadores. Quando uma mensagem é enviada, ela é enviada de um número IP para um destinatário com um número IP. Quando um conteúdo é acessado na Internet, ele é encontrado no servidor onde está hospedado por meio de seu endereço IP.

Países como a China e a Rússia desenvolveram, gradual e persistentemente, mecanismos técnicos próprios que não dependem de trâmites jurídicos internacionais, buscando não apenas a soberania sobre seus dados, mas o controle maciço dos conteúdos disponíveis em seus países. Goldsmith e Wu (2006) observam que, no começo dos anos 2000, a China já dispunha de um sistema eficiente de filtragem de conteúdos por meio de soluções oferecidas pela Cisco.

Essa empresa estadunidense, incontestavelmente hegemônica na produção de protocolos para a Internet dentro do IETF, prontificou-se a criar um sistema de filtro em seus roteadores nos pontos de interconexão dos provedores de Internet chineses com o exterior (Goldsmith; Wu, 2006, p. 93, tradução nossa). "Na prática, o governo fornece uma lista (a "lista de controle de acesso") de todos os sites banidos, identificados por seu endereço IP (por exemplo, 127.37.28.1) e seus URL (por exemplo, wutangclan.com)". ${ }^{8}$

6 Ex-técnico da CIA, Edward Snowden denunciou o sistema de espionagem dos EUA sobre diversos países, dentre os quais o Brasil, afetado pela gravação de conversas e pela interceptação de mensagens entre a presidenta Dilma Rousseffe seus assessores (Pétiniaud, 2014).

7 Internet Engineering Task Force: entidade de padronização reconhecida por suas qualidades ciberlibertarianas (Borsook, 1995).

8 "In practice, the government provides a list (the 'access controllist') of all of the banned sites, identified by their IP address (e.g., 127.37.28.1) and their URLs (e.g., wutangclan.com)" (Goldsmith; Wu, 2006, p. 93). 
Somando-se a isso, em 2006, a criação do próprio Sistema de Nomes de Domínio chinês resolveu a importante questão linguística de uma cultura baseada em ideogramas, mas, intensificou, com isso, os mecanismos de censura e vigilância de uma estrutura política autoritária. Em 2015, a China aprovou uma lei que exige o acesso aos dados de sua população aos provedores de conteúdo atuantes no país. Em 2017, essa normatização evoluiu de modo a exigir que os dados originados nesta jurisdição sejam estocados in loco (De Lespinois, 2017). Essa lei de cibersegurança levou a Apple a iniciar a construção de um data center no país, investindo um bilhão de dólares (Mozur; Wakabayashi; Wingfield, 2017). Não por acaso, os mecanismos de filtragem e censura da Internet chinesa receberam a alcunha de "Grande Muralha DNS da China" (Lowe; Winters; Marcus, 2007).

Embora não tenha um sistema de nomes de domínio próprio, a Rússia é igualmente reconhecida por uma Internet nacionalizada, chamada Runet. De acordo com Limonier (2014), o governo russo rejeita o termo "ciberespaço", entendendo-o como uma construção cultural estadunidense da década de 1990, e adota em seu lugar o conceito de "espaço informacional" para designar o conjunto de meios de comunicação, incluindo rádio e TV. De acordo com o pesquisador ucraniano Oleg Soldatov, ${ }^{9}$ o sistema de filtragem de conteúdos russo ocorre na última milha, entre o provedor de serviços de Internet e o usuário final. Soldatov cita quatro medidas legais do governo russo nos últimos anos que intensificaram a qualidade coercitiva que caracteriza a Runet:

(1) desde 2013, o governo está autorizado a suspender sites que veiculem informações consideradas extremistas sem ordem judicial (Lei Federal n. 398-FZ). A relatividade desse julgamento tange questões, por exemplo, como a criminalização da posse de imagens digitais que representem a Crimeia como pertencente à Ucrânia, conforme Oleg nos relatou;

(2) a partir de 2014, ocorreu um processo de desanonimização de blogueiros com grande número de seguidores, dado seu poder na opinião pública (Lei Federal n. 97-FZ);

(3) ainda em 2014, foi promulgada na Rússia a lei de nacionalização de dados, obrigando a guarda de dados de cidadãos russos em servidores localizados nessa jurisdição (Lei Federal n. 242-FZ). A adoção desse tipo de medida levou à suspensão da rede Linkedin no país, uma vez que a empresa não cumpriu a guarda de dados em solo russo (Lunden, 2017); e

(4) a partir de 2016, entrou em vigor uma norma que exige a retenção de dados a ser cumprida pelos provedores de Internet, os quais devem dispor informações retroativas ao governo, caso solicitadas (Lei Federal n. 374-FZ e n. 375-FZ).

Embora os casos russo e chinês sejam reconhecidos negativamente como exemplos de exercício de soberania para o cerceamento da liberdade de expressão de sua população, os resultados da Internet como expressão do livre mercado de dados foram gradualmente se revelando uma desvantagem política e econômica, uma geometria de poder assimétrica para o mundo dito democrático. Essas assimetrias levaram a União Europeia a formular um novo acordo com os EUA para regular a transferência de dados entre os países, denominado Privacy Shield. No âmbito nacional, os países da região têm desenvolvido, igualmente, medidas que garantam a proteção de seus dados, como novos requisitos para a prestação de serviço em nuvem por parte de empresas estadunidenses, de modo que os dados fiquem sob a guarda de administradores nacionais, como no caso alemão (Moody, 2015).

9 Informação fornecida por Soldatov, em entrevista concedida na Universidade de São Paulo, quando de sua visita à instituição, em julho de 2017. 
Ainda sobre os mecanismos jurídicos de controle de dados para finalidades jurisdicionais, Peterson, Gondree e Beverly (2011) citam os casos da Colúmbia Britânica e da Nova Escócia, onde os dados pessoais mantidos por instituições públicas não podem ser movidos para fora da fronteira canadense, e o caso australiano, cuja legislação permite a transferência de dados apenas para países com normativas equivalentes à sua.

Hazane (2013) resume os mecanismos de exercício jurisdicional na Internet em duas classes de estratégias, a primeira consistindo no controle dos recursos técnicos disponíveis no interior do território, a partir dos quais se define a experiência virtual, a segunda pautando-se em mecanismos de ordem jurídica pelos quais se regulam a produção e as ações no ciberespaço. Esse avanço da projeção das soberanias sobre o espaço virtual por meio do controle da Internet evoca a ideia de constituição de fronteiras virtuais no ciberespaço como um gradual decalque dos limites nacionais (De Lespinois, 2017).

Os exemplos acima são associados a mecanismos de territorialização da Internet por finalidades políticas, com o intuito de afirmar a soberania estatal dentro dos limites de suas fronteiras. Contudo, o emprego de sistemas de filtragem é igualmente utilizado para finalidades comerciais com base na discriminação geográfica. Quando um provedor de conteúdos oferece seus produtos a um usuário, a seleção do que é disponibilizado se pauta tanto em seus padrões de comportamento na Internet quanto no fator locacional, mesmo modus operandi da publicidade dirigida. Do ponto de vista da ação dessas empresas, a singularização da experiência na Internet realiza-se hoje para além das peculiaridades de um país. Ela se realiza na escala singular do usuário.

Considerando a crescente vinculação entre conteúdos da Internet e os contornos geográficos concretos, cabe perguntar se o ciberespaço, concebido como um espaço global, quase paralelo ao espaço geográfico, não estaria de algum modo e progressivamente tornandose uma experiência local cuja escala mínima seria a do indivíduo. E poderíamos indagar ainda qual seria, nessa tendência, a parcela de responsabilidade do Estado e a dos agentes privados, das grandes plataformas de Internet.

No que tange ao conflito entre soberanias, uma proposta de avanço no impasse das relações internacionais em tempos de Internet, apresentada por Svantesson (2015), consiste em resgatar os princípios que compõem a essência do conceito de jurisdição. $\bigcirc$ professor de direito propõe que, num contexto de redes transfronteiriças, a territorialidade, entendida como o espaço delimitado onde se exerce a autoridade, deixe de ser compreendida de modo literal e sejam procurados os fundamentos que lhe subjazem. Para o autor, os princípios de soberania, de cortesia e o dever de não ingerência devem ser utilizados como base das relações interestatais para estabelecer o direito ao emprego da jurisdição na Internet nas seguintes situações:

(1) quando existe uma conexão substancial entre o assunto e o Estado que procura exercer sua jurisdição; (2) quando o Estado que procura exercer jurisdição tem interesse legítimo na questão; e (3) quando o exercício da jurisdição é razoável, dado o equilibrio entre os interesses legítimos do Estado e outros interesses ${ }^{10}$ (Svantesson, 2015, p. 74).

10 "(1) there is a substantial connection between the matter and the State seeking to exercise jurisdiction; (2) the State seeking to exercise jurisdiction has a legitimate interest in the matter; and (3) the exercise of jurisdiction is reasonable given the balance between the State's legitimate interests and other interests" (De Lespinois, 2017, p. 50). 
O modelo apresentado por Svantesson (2015) aponta uma proposta principiológica para o direito internacional cuja abertura permite seu emprego em situações em que a resposta para se definir a jurisdição não se restrinja ao aspecto locacional dos fatos. Embora a proposição de Svantesson seja interessante como possibilidade de um novo paradigma jurídico internacional em tempos de Internet, as dimensões interna e externa da soberania no contexto das redes digitais transfronteiriças constituem um par indivisível, cuja relação está em constante mutação.

\section{Considerações finais}

O controle de um território pressupõe um saber sobre esse espaço. $\bigcirc$ soberano era aquele que dispunha de métodos para administrar seu território por meio de tecnologias de quantificação, recenseamento e estatísticas que permitiam tornar esse espaço acessível ao conhecimento e passível de controle político (Gottmann, 1952). As redes digitais trouxeram o desencaixe desse exercício da soberania pelo saber territorial, levando à coexistência de múltiplas territorialidades externas que disputam a captura de informações sobre o território nacional. As territorialidades digitalizadas que desafiam o exercício da soberania tradicional atuam estrategicamente no conhecimento informacional do território.

As transformações que a Internet vem sofrendo passam a demandar novas formas de aplicação da soberania em nível interno, que impactam inevitavelmente as relações externas. $\mathrm{Na}$ medida em que os aplicativos deixam de ser plataformas de relações sociais e passam a mediar relações de trabalho e de recursos de um país, como as empresas Uber e Airbnb, a sobreposição de jurisdições se cristaliza no conflito sobre a definição das condições de reprodução de vida de uma população. Nesse caso, trata-se de dados de transporte e de circulação, regulação do trabalho e geração de valor: informações e valores pertencentes a uma jurisdição delimitada por fronteiras westfalianas e que são apropriadas por outra jurisdição. Nova forma de exercício de uma multiterritorialidade transnacional empregando o ciberespaço, produzindo espaços com territórios múltiplos e plurijurisdicionais.

Para De Lespinois (2017), coexistem três leituras políticas do ciberespaço que, por vezes, conflitam entre si: (1) uma perspectiva libertariana, baseada no anseio de um espaço virtual independente dos governos, (2) uma perspectiva liberal, que concebe o ciberespaço como uma rede de livre circulação (e exploração) de dados, e (3) uma perspectiva westfaliana, que percebe o espaço virtual como um locus de projeção das disputas entre soberanias. "O modelo libertariano está em declínio, enquanto o modelo liberal triunfa hoje, e se perfila o modelo westfaliano" "I (De Lespinois, 2017, p. 50, tradução nossa).

reconhecimento de que o espaço nacional e sua esfera normativa são um espaço pertinente - e cada vez mais presente - para a definição das qualidades do ciberespaço, recoloca as redes digitais dentro de um escopo de investigação que ultrapassa a simples interpretação dessa tecnologia como um fenômeno puramente transnacional, convidando a reflexões que considerem a emergência de espacialidades que resultam de uma interpenetração de escalas, do local ao global, passando inapelavelmente pelo nacional. Nessa perspectiva, o território jurisdicional, em suas diversas conformações, mostra-se uma categoria relevante para observamos os contornos

11 "Le modèle libertarien est en déclin, tandis que le modèle libéral triomphe aujourd' hui et que se profile le modèle westphalien" (De Lespinois, 2017, p. 50). 
socioespaciais do ciberespaço, assim como o ciberespaço contribui para repensarmos o conceito de território na era das redes digitais.

\section{Referências}

ANTAS JR., R. M. Território e regulação: espaço geográfico, fonte material e nãoformal do direito. São Paulo: Fapesp/Humanitas, 2005.

ANTAS JR., R. M. Elementos para uma discussão epistemológica sobre a regulação no território. Geousp - Espaço e Tempo (Online), n. 16, p. 81-86, 2004.

ARROYO, M. Território, mercado e Estado: uma convergência histórica. GEOgraphia, v. 6, n. 12, p. 49-66, 2004.

BADIE, B. La fin des territoires westphaliens. In: LE TERRITOIRE, LIEN OU FRONTIERE? 1995, Paris. Anais... Paris: L'Orstom, 1995a. Disponível em: http:// deey.free.fr/documents/Documents\%20territoires/Territoire, \%20lien\%20ou\%20 fronti\%C3\%A8re/TEXTES/ACTES.PDF. Acesso em: 8 nov. 2019.

BADIE, B. O fim dos territórios. Lisboa: Instituto Piaget, 1995b.

BARLOW, J. P. A Declaration of the Independence of Cyberspace. Electronic Frontier Foundation. Davos, 8 Feb. 1996. Disponível em: https://www.eff.org/cyberspaceindependence. Acesso em: 8 nov. 2019.

BORSOOK, P. How Anarchy Works. Wired, 1 out. 1995. Disponível em: https:// paulinaborsook.com/PDF-disk-1/How\%20Anarchy\%20Works_WIRED.pdf. Acesso em: 8 nov. 2019.

DE LA CHAPELLE, B. Gouvernance Internet: tensions actuelles et futurs possibles. Politique étrangère, v. été, n. 2, p. 249-261, 2012.

DE LESPINOIS, J. La territorialisation du cyberespace: la fin de la mondialisation? Prospective et stratégie, v. 1, n. 8, p. 47-56, 2017.

ELLINGSEN, N. The Microsoft Ireland Case: A Brief Summary. Lawfare, 15 July 2016. Disponível em: https://www.lawfareblog.com/microsoft-ireland-case-briefsummary. Acesso em: 8 nov. 2019.

GIBSON, W. Neuromancer. São Paulo: Aleph, 2008[1984].

GOLDSMITH, J. L.; WU, T. Who controls the Internet? Illusions of a borderless world. New York: Oxford University Press, 2006.

GOTTMANN, J. La politique des états et leur géographie. Paris: Colin, 1952.

GROS, M.-J. Vente d'objets nazis: Yahoo s'estime hors la loi française. Libération. 5 févr. 2004.

HAESBAERT, R. O mito da desterritorialização: do "fim dos territórios" à multiterritorialidade. Rio de Janeiro: Bertrand Brasil, 2007.

HAZANE, E. Internet ouvert et souveraineté numérique: existe-t-il des frontières dans le cyberespace? In: DOSSÉ, S. (Ed.). Le cyberespace: nouveau domaine de la pensée stratégique. Paris: Economica, 2013. p. 81-88. 
LACOSTE, Y. Encore et toujours des territoires. In: LE TERRITOIRE, LIEN OU FRONTIERE? 1995, Paris. Anais... Paris: L'Orstom, 1995. Disponível em: http:// deey.free.fr/documents/Documents\%20territoires/Territoire, \%20lien\%20ou\%20 fronti\%C3\%A8re/TEXTES/ACTES.PDF. Acesso em: 8 nov. 2019.

LEAL, A. Ministério da Cultura aciona Facebook por censurar foto de casal indígena. Agência Brasil. Brasilia, 17 abr. 2015. Disponível em: http://agenciabrasil.ebc.com. $\mathrm{br} /$ cultura/noticia/2015-04/ministerio-da-cultura-aciona-facebook-por-censurarfoto-de-casal-indigena. Acesso em : 8 nov. 2019.

LIMONIER, K. La Russie dans le cyberespace: représentations et enjeux. Hérodote, v. 152-153, n. 1, p. 140-160, 20 jun. 2014.

LOWE, G.; WINTERS, P.; MARCUS, M. L. The Great DNS Wall of China. MS, New York University, v. 21, p. 1-7, 2007. Disponível em: https://censorbib.nymity.ch/ pdf/Lowe2007a.pdf. Acesso em: 8 nov. 2019.

LUNDEN, I. Russia says "nyet", continues Linkedin block after it refuses to store data in Russia. Tech Crunch. 7 Mar. 2017. Disponível em: https://techcrunch. com/2017/03/07/russia-says-nyet-continues-linkedin-block-after-it-refuses-tostore-data-in-russia/. Acesso em: 8 nov. 2019.

MASSEY, D. Pelo espaço. Rio de Janeiro: Bertrand, 2008.

MOODY, G. Microsoft building data centers in Germany that US government can't touch. Ars Technica. 11 dez. 2015. Disponível em: https://arstechnica.com/informationtechnology/2015/11/microsoft-is-building-data-centres-in-germany-that-the-usgovernment-cant-touch/. Acesso em: 8 nov. 2019.

MOZUR, P.; WAKABAYASHI, D.; WINGFIELD, N. Apple Opening Data Center in China to Comply With Cybersecurity Law. The New York Times, 12 jul. 2017. Disponível em: https://www.nytimes.com/2017/07/12/business/apple-china-datacenter-cybersecurity.html. Acesso em: 8 nov. 2019.

PETERSON, Z. N. J.; GONDREE, M.; BEVERLY, R. A Position Paper on Data Sovereignty: The Importance of Geolocating Data in the Cloud. In: Hot Cloud'11: Proceedings of the 3rd USENIX Workshop on Hot Topics in Cloud Computing: Portland, 2011. p. 1-5. Disponível em: https://www.usenix.org/legacy/events/ hotcloudl1/tech/final_files/Peterson.pdf. Acesso em: 8 nov. 2019.

PÉTINIAUD, L. Cartographie de l'affaire Snowden. Hérodote, v. 152-153, n. 1, p. 3542, 2014.

PIRES, H. F. Estados nacionais, soberania e regulação da internet. Scripta Nova - Revista Electrónica de Geografía y Ciencias Sociales, v. 16, n. 418, 2012.

SVANTESSON, D. J. B. A new jurisprudential framework for jurisdiction: beyond the Harvard draft. AJIL Unbound, v. 109, p. 69-74, 2015.

THIELMAN, S. Microsoft case: DoJ says it can demand every email from any US-based provider.

The Guardian.9 Sept. 2015. Disponível em: https://www.theguardian.com/technology/2015/ sep/09/microsoft-court-case-hotmail-ireland-search-warrant. Acesso em: 8 nov. 2019. 